\title{
5-Hydroxytryptamine and human small intestinal motility: effect of inhibiting 5-hydroxytryptamine reuptake
}

\author{
D A Gorard, G W Libby, M J G Farthing
}

\begin{abstract}
Parenteral 5-hydroxytryptamine stimulates small intestinal motility, but the effect of continuous stimulation with 5-hydroxytryptamine on the human migrating motor complex is unknown. Using a selective 5-hydroxytryptamine reuptake inhibitor, paroxetine, this study investigated the effect of indirect 5-hydroxytryptamine agonism on fasting small intestinal motility and transit. Eight healthy subjects were studied while receiving paroxetine $30 \mathrm{mg}$ daily for five days and while receiving no treatment, in random order. Ambulant small intestinal motility was recorded from five sensors positioned from the duodenojejunal flexure to the ileum for 16-18 hours. Paroxetine reduced the migrating motor complex periodicity mean (SEM) from 81 (6) $\mathrm{min}$ to 67 (4) $\mathrm{min}(\mathrm{p}<0.05)$, and increased the propagation velocity of phase III from 3.1 to $4.7 \mathrm{~cm}$ / min in the proximal jejunum $(p<0.01)$, and from 1.6 to $3.4 \mathrm{~cm} / \mathrm{min}$ distally $(p<0.001)$. Orocaecal transit time measured by lactulose hydrogen breath test was reduced by paroxetine from $70(9) \mathrm{min}$ to $48(7) \mathrm{min}(\mathrm{p}<0.05)$. These data suggest that 5 -hydroxytryptamine participates in the control of migrating motor complexes in humans, and that selective 5hydroxytryptamine reuptake inhibitors have a prokinetic action in the human small intestine. (Gut 1994; 35: 496-500)
\end{abstract}

The gastrointestinal tract is the main source of 5hydroxytryptamine (5-HT) in humans. In the small intestine, 5-HT is found predominantly within the enterochromaffin cells of the mucosa, but significant amounts of 5-HT are also found within the myenteric plexus. In addition to its role in the intestinal secretion of water and electrolytes, and its influence on mesenteric blood flow, 5-HT has prominent effects on intestinal motility. There is compelling evidence that $5-\mathrm{HT}$ is a neurotransmitter within the enteric nervous system. ${ }^{12}$ Enteric serotonergic neurones are interneurones, innervating ganglion cells of the submucosal and myenteric plexuses.

5-HT given intravenously over short periods of time has been shown to alter human small intestinal motility ${ }^{3-7}$ although such studies predated the recognition of the migrating motor complex in humans. ${ }^{8}$ The migrating motor complex is a distally migrating pattern of motility seen during the fasting state in mammals. ${ }^{9}$ The migrating motor complex is programmed by the circuitry of the enteric nervous system, but the oscillatory mechanism controlling its cyclical nature is poorly understood. ${ }^{10}$ In animals, migrating motor complex cycling can be modified by administration of 5-HT, its precursor 5-hydroxytryptophan, and its antagonists. ${ }^{11-14}$ The effect of 5-HT on the migrating motor complex in humans has not been studied. Tachyphylaxis to 5-HT given intravenously, ${ }^{45}$ and associated cardiovascular and pulmonary responses limit prolonged infusion of 5-HT in humans. The effect, however, of 5-HT agonism on human small intestinal motor function might be alternatively investigated using a selective 5-HT reuptake inhibitor. Paroxetine selectively inhibits the neuronal reuptake of 5-HT, increasing the availability of synaptic 5-HT. Its ability to inhibit 5-HT reuptake exceeds its ability to inhibit noradrenaline reuptake by a factor of $320,{ }^{15}$ making it four to five hundred times as selective as the standard tricyclic antidepressants imipramine and amitriptyline. Unlike traditional tricyclic drugs, paroxetine has negligible affinity for muscarinic cholinergic receptors and does not bind at other neurotransmitter receptor sites. Although paroxetine is used for its action in the central nervous system, enteric 5-HT neurones resemble central 5-HT neurones in their response to 5-HT reuptake inhibitors. ${ }^{16}$ The aim of this study was to use the 5-HT reuptake inhibitor paroxetine as an indirect 5-HT agonist, to examine the longer term effects of 5-HT on human small intestinal motility and transit.

\section{Methods}

Eight healthy volunteers (five men, median age 25 years, range 23-33) without history of gastrointestinal symptoms or surgery were studied. Each had small intestinal motility and transit studies while receiving no treatment and while taking paroxetine in a randomised order. For the paroxetine studies, a single daily dose of $30 \mathrm{mg}$ oral paroxetine was taken for five days. The transit and motility studies were performed on the fourth and fifth days respectively. Drug free (control) studies and those where paroxetine was given were separated by at least three weeks. All subjects gave written informed consent and the study was approved by the research ethics committee of the City and Hackney Health District.

\section{SMALL INTESTINAL MOTILITY}

Small intestinal motility was recorded using a fine $(2.7 \mathrm{~mm}$ diameter $)$ flexible catheter incorporating five miniature electronic strain gauge transducers (Gaeltec Ltd, Isle of Skye, UK). The transducers were sited at $3 \mathrm{~cm}, 48 \mathrm{~cm}$, 
Figure 1: Motility recording from the five small intestinal sites. Phase III activity front of the migrating motor complex propagates distally, preceded by irregular phase II activity and followed by quiescence of phase I. Site Df represents pressure at the duodenojejunal flexure, sites $\mathcal{F}_{1}, \mathcal{F}_{2}, \mathcal{F}_{3}$, and I represent pressure at $15 \mathrm{~cm}, 30 \mathrm{~cm}, 50$ $\mathrm{cm}$, and $95 \mathrm{~cm}$ aborally.

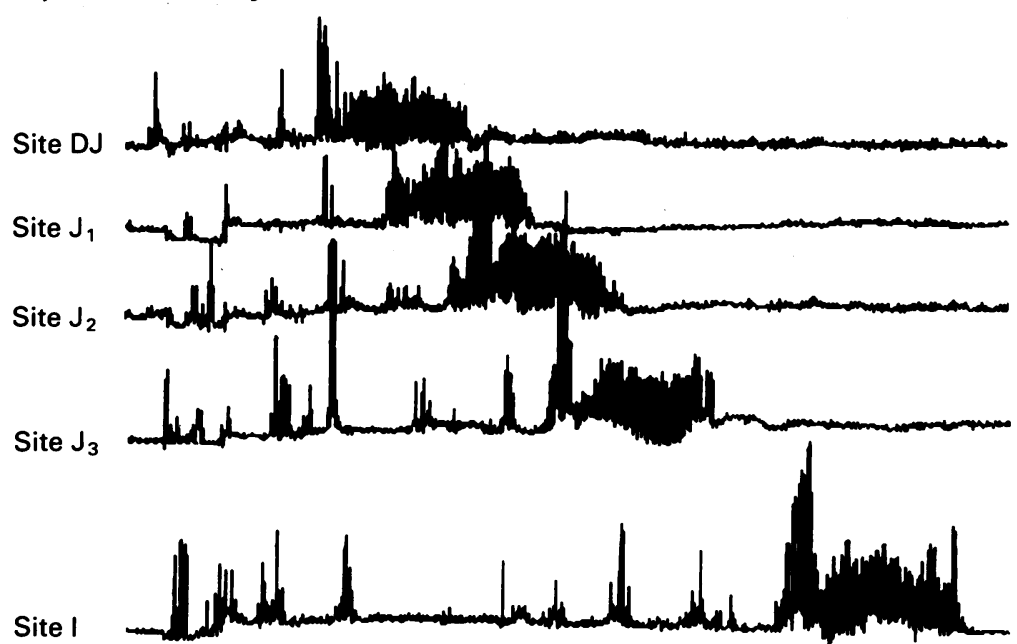

$50 \mathrm{~mm} \mathrm{Hg}$
$68 \mathrm{~cm}, 83 \mathrm{~cm}$, and $98 \mathrm{~cm}$ from the distal tip of the catheter. Fasting subjects were nasally intubated with the catheter at 0900 . The tip of the catheter was guided through the pylorus using fluoroscopy, and a small balloon attached to the tip was inflated with air to facilitate the propagative activity of the intestine in pulling the catheter distally. Distal migration of the catheter continued until the most proximal transducer was sited at the duodenojejunal flexure (site DJ) and the other four transducers were $15 \mathrm{~cm}$ (site $\mathrm{J}_{1}$ ), $30 \mathrm{~cm}$ (site $\mathrm{J}_{2}$ ), $50 \mathrm{~cm}$ (site $\mathrm{J}_{3}$ ), and $95 \mathrm{~cm}$ (site I) distal to the duodenojejunal flexure. The balloon was then deflated, any redundant catheter was withdrawn from the stomach, and the catheter secured to the face with tape. Recording of small intestinal motility then began, with pressure sampling occurring at 8 Hertz. Data were stored digitally in a portable lightweight recorder (7-MPR recorder, Gaeltec Ltd, Isle of Skye, UK) carried in a holster over the subject's shoulder.

Motility was recorded for 16-18 hours during which subjects were ambulant but discouraged from taking vigorous exercise because intense physical activity masks the intestinal intraluminal pressure recording with external pressure artefact. Subjects spent the rest of the day and night at home and returned the next morning. They were not allowed to eat, but were permitted small amounts of clear fluids, which were recorded. When each recording was completed, data were transferred from the 512 Kbyte memory of the recorder to a computer for graphic display and analysis.

contractile activity. Migrating motor complex cycle length or periodicity was defined as the time interval between the onset of successive phase III fronts occurring at site $J_{1}$ in the proximal jejunum. This site was used for calculation of periodicity, as phase III fronts occur maximally in the proximal jejunum. ${ }^{17}$ Propagation velocity of phase III between adjacent sensors was calculated by dividing the distance between sensors by the time taken to pass from one sensor to the next. The duration of each activity front at each sensor was measured from the onset of regular contractions to quiescence. The maximum contractile rate during phase III at each site was determined. The extent to which each phase III migrated aborally, and the percentage of phase III fronts originating at sites beyond site $\mathrm{J}_{1}$ were noted.

A motility index for non-phase III - that is, combined phase I and II - activity in the proximal jejunum (site $\mathrm{J}_{1}$ ), was calculated using computer assisted analysis. Motility index was calculated as:

mean amplitude of contraction $(\mathrm{mm} \mathrm{Hg}) \times$ mean duration $(\mathrm{min}) \times$ no of contractions time (min)

This analysis excluded contractile waves $<15$ $\mathrm{mm} \mathrm{Hg}$ above the current baseline, which might represent respiratory excursion. Simultaneous brief contractions seen at all sensors as a result of artefacts such as coughing were similarly excluded from analysis.

Characteristics of migrating motor complexes recorded during the day were compared with those occurring at night (2300-0500).

\section{ANALYSIS OF MOTILITY}

Motility data were analysed without knowledge of whether control or paroxetine recordings were being studied. Contractile patterns were analysed visually (Fig 1). The activity front or phase III of the migrating motor complex was recognised as at least three minutes of uninterrupted phasic contractions at the maximum rate for that intestinal site, followed by motor quiescence (phase I). Phase II consisted of irregular

\section{OROCAECAL TRANSIT TIME}

On a separate occasion, orocaecal transit time was determined after an overnight fast and a 20 $\mathrm{ml}$ mouthwash with $0.2 \% \mathrm{wt} / \mathrm{vol}$ chlorhexidine gluconate. End expiratory breath samples were analysed before and at 10 minute intervals after ingestion of $20 \mathrm{ml}(13.4 \mathrm{~g})$ lactulose for hydrogen concentration (Hydrogen monitor, GMI Medical Ltd, Renfrew, UK). Orocaecal transit time was defined as the period of time between lactulose ingestion and a sustained $(>10 \mathrm{ppm}$ above baseline) rise in breath hydrogen.

\section{STATISTICAL ANALYSIS}

Data are expressed as mean (SEM). Statistical significance was assessed using analysis of variance, and Student's $t$ tests for paired and unpaired data.

\section{Results}

Eighty one complete migrating motor complexes were recorded while subjects were drug free (control), and 102 complete migrating motor complexes were recorded while subjects received paroxetine. Overall migrating motor complex periodicity at the proximal jejunum (site $\mathrm{J}_{1}$ ) was 81 (6) min during the control study, and 67 (4) min while receiving paroxetine $(\mathrm{p}<0.05)$. The normal shortening of migrating motor complex periodicity at night ${ }^{18}$ occurred during control and paroxetine studies. Migrating motor com- 


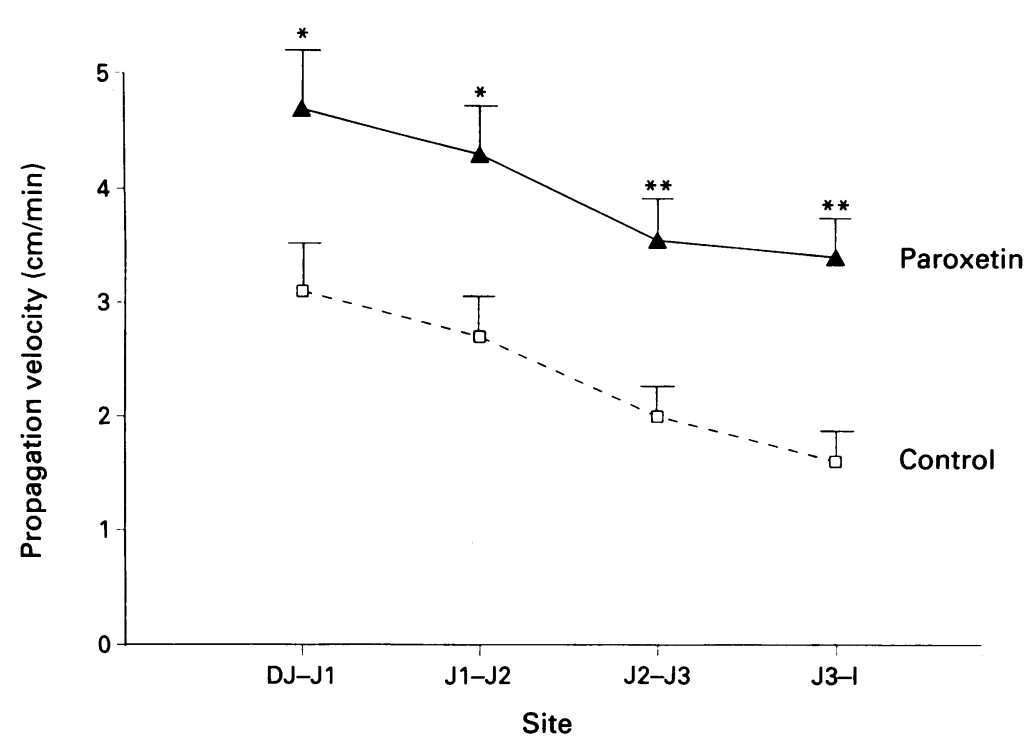

Figure 2:-Propagation velocity of phase III between adjacent pairs of sensors while receiving no drug (control) and paroxetine. Site Df duodenojejunal flexure, sites $\mathcal{F}_{1}, \mathcal{F}_{2}, \mathcal{F}_{3}$ jejunum, site I ileum. ${ }^{\star} p<0.01$ compared with control velocity; ${ }^{\star \star} p<0.001$ compared with control velocity.

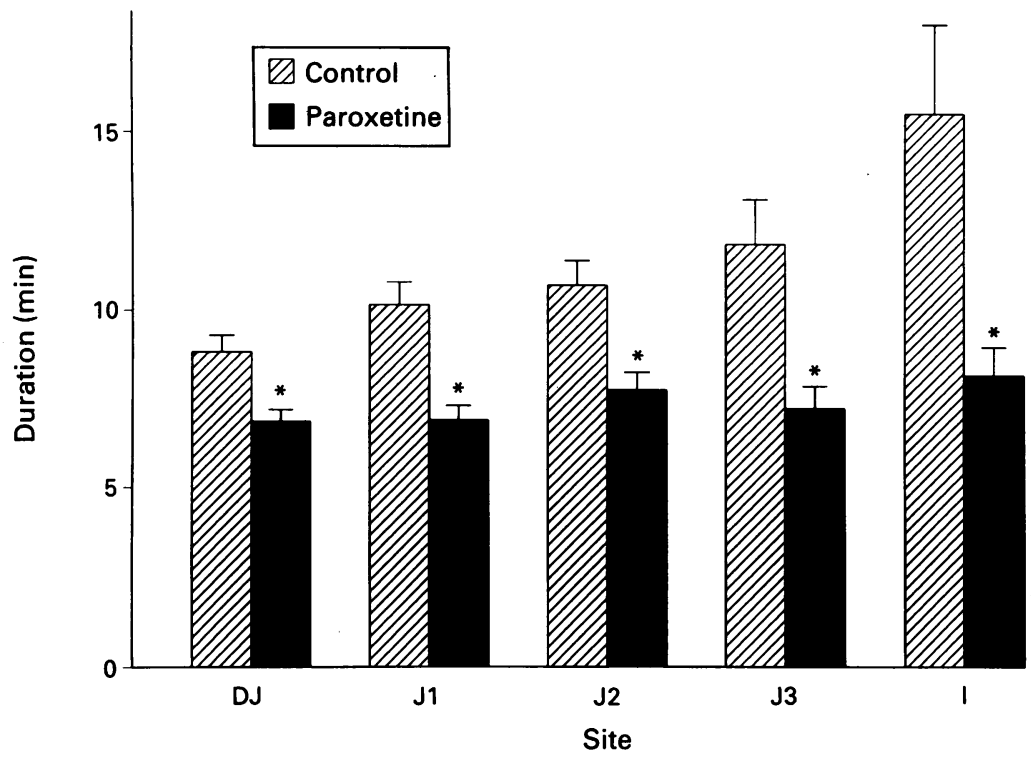

Figure 3: Duration of phase III at each recording site while taking no drug (control) and paroxetine. Site $D \mathcal{f}$ duodenojejunal flexure, sites $\mathfrak{F}_{1}, \mathcal{F}_{2}, \mathcal{F}_{3}$ jejunum, site I ileum. ${ }^{\star} p<0 \cdot 01$ compared with baseline duration.

plex periodicity in the control study was 93 (10) min diurnally, $68(5)$ min nocturnally $(\mathrm{p}<0.05)$, and with paroxetine was 75 (6) min diurnally, 59 (5) min nocturnally $(p<0.05)$. While awake, the periodicity of migrating motor complex cycles during which fluids were ingested did not differ from the periodicity of cycles during which subjects were strictly fasted. The volume of clear fluid consumed during control recordings was $420(50) \mathrm{ml}$, and while receiving paroxetine was $470(40) \mathrm{ml}$.

Maximum contractile rate and mean amplitude of phase III contractions at each small intestinal recording site

\begin{tabular}{|c|c|c|c|c|c|}
\hline & Site $D \mathcal{F}$ & Site $\mathcal{F}_{1}$ & Site $\tilde{f}_{2}$ & ${\text { Site } \mathcal{F}_{3}}_{1}$ & Site I \\
\hline \multicolumn{6}{|l|}{ Maximum phase III contractile rate } \\
\hline Baseline (contractions/min) & $11 \cdot 0(0 \cdot 2)$ & $10 \cdot 8(0 \cdot 1)$ & $10 \cdot 6(0 \cdot 2)$ & $10 \cdot 2(0 \cdot 1)$ & $9 \cdot 9(0 \cdot 2)$ \\
\hline \multirow{2}{*}{\multicolumn{6}{|c|}{ Mean phase III amplitude }} \\
\hline & & & & & \\
\hline Paroxetine (mm Hg) & $33 \cdot 0(1 \cdot 5)$ & $32 \cdot 7(1 \cdot 5)$ & $33 \cdot 7(1 \cdot 4)$ & $32.5(1.0)$ & $38.8(1.9)$ \\
\hline
\end{tabular}

Data represent mean (SEM). Site DJ represents sensor at duodenojejunal flexure, sites $\mathrm{J}_{1}, \mathrm{~J}_{2}, \mathrm{~J}_{3}$, and I represent sensors at $15 \mathrm{~cm}, 30 \mathrm{~cm}, 50 \mathrm{~cm}$, and $95 \mathrm{~cm}$ aborally.

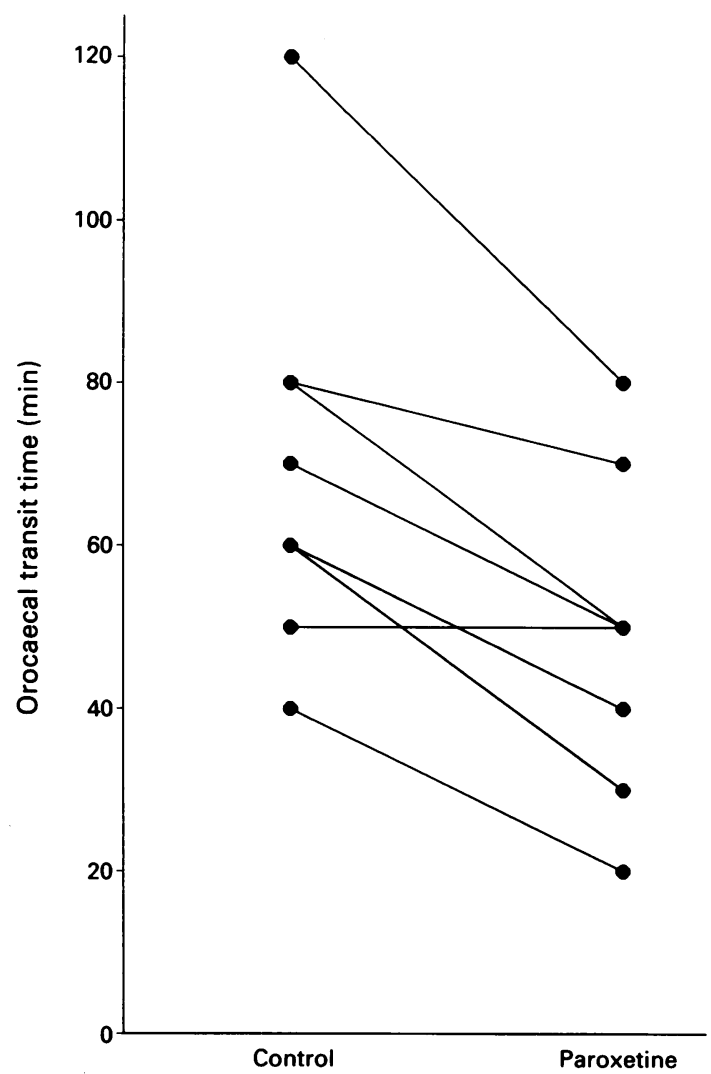

Figure 4: Orocaecal transit time while receiving no drug (control) and while taking paroxetine.

\section{PHASE III CHARACTERISTICS}

As phase III activity fronts progressed aborally, their propagation velocity decreased, a finding consistent with reports from other workers. ${ }^{17}$ The propagation velocity of phase IIIs between pairs of adjacent sensors was increased by paroxetine (Fig 2). Paroxetine increased the propagation velocity from 3.1 to $4.7 \mathrm{~cm} / \mathrm{min}$ in the proximal jejunum $(\mathrm{p}<0.01)$, and from 1.6 to $3.4 \mathrm{~cm} / \mathrm{min}$ distally $(\mathrm{p}<0.001)$. During the control study, the time duration for which phase IIIs were recorded at each successive sensor increased with distal propagation (Fig 3). During the paroxetine study, the faster propagating phase IIIs were present at all the sensors for a shorter duration of time $(\mathrm{p}<0.01)$.

The maximum contractile frequency within phase III decreased with aboral propagation of phase III, and was unaffected by paroxetine (Table). The mean amplitude of phase III contraction was not influenced by paroxetine (Table). Phase III amplitude recorded in the ileum with and without paroxetine was greater than phase III amplitude recorded more proximally.

During the control recording, $24 \%$ of phase III activity fronts recorded at site DJ and migrating to at least the next two sensors, $J_{2}$, failed to reach the most distal recording site in the ileum, site I. While receiving paroxetine a similar proportion, $21 \%$ of phase III fronts failed to propagate as far as site I. During the control study, $6 \%$ of phase III activity fronts originated at site $\mathrm{J}_{2}$ or $\mathrm{J}_{3}$ and were recorded at a minimum of two consecutive sensors. While receiving paroxetine a similar proportion, $9 \%$ of phase III fronts started this far distally. 


\section{NON-PHASE III MOTILITY INDEX}

During the day, the motility index for non-phase III activity was not different during the control study, $6 \cdot 8(2 \cdot 2)$, and the paroxetine study, $4 \cdot 2$ $(1 \cdot 1)$. At night the motility index for non-phase III activity was also similar during the control study $2 \cdot 4(0 \cdot 5)$, and the paroxetine study $2 \cdot 0$ $(0 \cdot 4)$. These nocturnal motility indexes were lower $(p<0.05)$ than the respective diurnal motility indexes, a consequence of diminished phase II activity at night. ${ }^{18}$

\section{OROCAECAL TRANSIT TIME}

Control orocaecal transit time measured by lactulose hydrogen breath test was 70 (9) $\mathrm{min}$ (Fig 4). Paroxetine reduced orocaecal transit time to $48(7) \min (\mathrm{p}<0.05)$.

\section{Discussion}

We have shown that indirect 5-HT agonism using a 5-HT reuptake blocker influences human small intestinal fasting motility and transit. Short term intravenous administration of 5-HT to humans is known to stimulate small intestinal contractile activity..$^{3-6}$ Within minutes of intravenous $5-\mathrm{HT}$, contractions occurring at a maximal rate are seen in the jejunum..$^{45}$ The effects of 5-HT on migrating motor complex cycling, however, have been only studied in animals. In sheep, the 5-HT precursor 5-hydroxytryptophan decreases the periodicity of migrating motor complex cycles. ${ }^{11}$ In the dog, intravenous 5-HT causes increased small intestinal phasic contractions. ${ }^{12}$ The canine migrating motor complex may be replaced with continuous phase III like contractions, ${ }^{20}$ particularly at high doses of 5-HT. ${ }^{21}$ Low dose 5-hydroxytryptophan decreases migrating motor complex periodicity in rats, whereas a higher dose disrupts the migrating motor complex. ${ }^{14}$ In the opossum, intravenously infused 5-HT decreases the periodicity of migrating motor complexes in a dose dependent manner, and increases the propagation velocity of phase III activity fronts. ${ }^{13}$ These animal studies suggest that 5-HT participates in migrating motor complex cycling. Furthermore, selective destruction of 5-HT enteric neurones in the rat disrupts the migrating motor complex. ${ }^{22}$

In this study, ambulant recordings of human small intestinal motility have shown that 5-HT agonism with paroxetine affects the human migrating motor complex. Migrating motor complex periodicity was decreased and the propagation velocity of phase III fronts was increased by paroxetine. Although sleeving of the small intestine over the catheter may lead to an underestimate of calculated propagation velocity, this is equally likely to have occurred in recordings with and without paroxetine.

The more frequent and faster propagating migrating motor complexes were associated with a shortened orocaecal transit time. Using lactulose alone to measure orocaecal transit time does not interrupt the fasting migrating motor complex pattern. This technique of measuring drug induced differences of orocaecal transit time is perhaps more relevant to this study than one using a test meal, because we were investigating drug induced differences of fasting motility. Orocaecal transit time comprises gastric emptying as well as small intestinal transit time. Liquids begin to empty from the stomach almost immediately after ingestion, however, and orocaecal and duodenocaecal transit times of lactulose are not different. ${ }^{23}$ Thus the decrease in orocaecal transit time by paroxetine cannot be a result of an increase in gastric emptying. Furthermore, studies using 5- $\mathrm{HT},{ }^{6}{ }^{5}-\mathrm{HT}_{3}$ antagonists, ${ }^{24}$ and $5-\mathrm{HT}_{1 \mathrm{P}}$ agonists/antagonists ${ }^{2}$ suggest that 5-HT agonism may delay rather than promote gastric emptying. Therefore the shortening of orocaecal transit time by paroxetine truly reflects a shortened small intestinal transit time. Whether paroxetine reduces small intestinal transit in the fed state cannot be inferred from this study. Any similar prokinetic effect in the small intestine during the postprandial state might be accompanied by a delay in the gastric emptying of a solid meal induced by 5-HT agonism.

The possibility that paroxetine might be exerting its effects on small intestinal motor activity by a non-serotonergic mechanism is remote. Radioligand binding studies show that paroxetine does not directly interact with $\alpha_{1}, \alpha_{2}$, or $\beta$ adrenoceptors, dopamine, histamine or even 5-HT receptor subtypes. ${ }^{1525}$ Although it does have very weak affinity for muscarinic cholinergic receptors, any anti-muscarinic effect produced by paroxetine might be expected to impede migrating motor complex cycling ${ }^{26}$ leading to lengthening of migrating motor complex periodicity $^{27}$ and delayed orocaecal transit time. ${ }^{28}$ Equally paroxetine's weak inhibition of noradrenaline reuptake and consequent increased availability of synaptic noradrenaline is unlikely to account for the changes seen in small intestinal motility and transit. Stimulation of $\alpha_{1}$ and $\beta$ adrenoceptors leads to an increase rather than a decrease in orocaecal transit time ${ }^{2930}$ while the prolongation of orocaecal transit time by $\alpha_{2}$ receptor stimulation is not significant. ${ }^{31}$

The nature of this study precludes precise identification of the site of 5-HT action or the 5-HT receptor subtype(s) that are responsible. Paroxetine acts centrally to achieve its effect on mood. Serotonergic neurones of the enteric nervous system resemble those of the central nervous system, however, and are similarly affected by reuptake inhibitors. ${ }^{16}$ In sheep, reduction in migrating motor complex periodicity by methysergide was unchanged by sectioning the extrinsic nerve supply to the gut. ${ }^{11}$ This suggests that pharmacological manipulations of the migrating motor complex with 5-HT agonists/antagonists given systemically occur at the level of the enteric nervous system.

If it is assumed that paroxetine's effects on small intestinal motility and transit are a result of its actions on the enteric nervous system, we can only speculate as to which stimulated 5-HT receptor subtype(s) is involved. Of the known subtypes, $5-\mathrm{HT}_{1 \mathrm{~A}}, 5-\mathrm{HT}_{1 \mathrm{P}}, 5-\mathrm{HT}_{3}$, and $5-\mathrm{HT}_{4}$ receptors have been identified in the enteric nervous system. In rats there is some evidence that $5-\mathrm{HT}_{3}$ receptors participate in migrating 
motor complex cycling, because a 5-HT receptor antagonist prolongs the periodicity of jejunal migrating motor complexes. ${ }^{14}$ In dogs, $5-\mathrm{HT}_{3}$ receptor antagonism has no effect on jejunal migrating motor complexes ${ }^{32} 33$ but inhibits gastric and duodenal phase III. ${ }^{32}$ In humans $5-\mathrm{HT}_{3}$ receptor antagonism does not affect duodenal migrating motor complexes, ${ }^{34}$ or small intestinal transit time. ${ }^{3536}$ Therefore these human studies do not support a role for $5-\mathrm{HT}_{3}$ receptors in controlling the migrating motor complex in humans. Most in vivo studies, however, of healthy subjects with $5-\mathrm{HT}_{1}$ like, $5-\mathrm{HT}_{2}$, and $5-\mathrm{HT}_{3}$ receptor antagonists fail to show any dramatic effects on motility, ${ }^{37}$ suggesting that 5-HT may have a rather subtle modulatory function in health.

In summary, this study has shown that 5-HT agonism leads to more frequent and faster propagating migrating motor complexes, and implicates the participation of 5-HT in the control of human migrating motor complex cycling. The accelerated orocaecal transit time produced by 5 -HT reuptake inhibition suggests that selective 5-HT reuptake inhibitors may have a prokinetic use in disorders of small intestinal transit.

1 Gershon MD, Sherman DL. Noradrenergic innervation of serotonergic neurons in the myenteric plexus. $\mathcal{7}$ Comp Neurol 1987; 259: 193-210.

2 Gershon MD, Wade PR, Kirchgessner AL, Tamir H. 5-HT receptor subtypes outside the central nervous system. Roles in the physiology of the gut. Neuropsychopharmacology 1990; 3: 385-95.

3 Hendrix TR, Atkinson M, Clifton JA, Ingelfinger FJ. The effect of 5-hydroxytryptamine on intestinal motor function effect of 5-hydroxytryptamine on in

4 Haverback BJ, Davidson JD. Serotonin and the gastrointestinal tract. Gastroenterology 1958; 35: 570-7.

Debray C, Besançon F. L'intervention de la sérotonine (5-hydroxytryptamine) dans la motricité physiologique de l'intestin grêle de l'homme. Recherches électromanométriques. F Physiol (Paris) 1961; 53: 525-41.

6 Misiewicz JJ, Waller SL, Eisner M. Motor responses of human gastrointestinal tract to 5-hydroxytryptamine in vivo and in vitro. Gut 1966; 7: 208-16.

7 Labo G, Barbara L, Lanfranchi GA, Bortolotti M, Miglioli M. Modification of the electrical activity of the human intestine after serotonin and caerulein. Am f Dig Dis 1972; 17: 363-

8 Vantrappen G, Janssens J, Hellemans J, Ghoos Y. The interdigestive motor complex of normal subjects and patients with bacterial overex of the sull intestine. 7 Clin Invest 1977; 59: 1158-66.

9 Szurszewski JH. A migrating electric complex of the canine small intestine. Am F Physiol 1969; 217: 1757-63.

10 Sarna SK. Cyclic motor activity; migrating motor complex: 1985. Gastroenterology 1985; 89: 894-913.

11 Ruckebusch Y, Bardon $\mathrm{T}$. Involvement of serotonergic mechanisms in initiation of small intestine cyclic motor events. Dig Dis Sci 1984; 29: 520-7.

12 Ormsbee HS, Silber DA, Hardy FE. Serotonin regulation of the canine migrating motor complex. F Pharmacol Exp Ther 1984; $231: 436-40$.

13 Coelho JCU, Gouma DJ, Moody FG, Li YF, Weisbrodt NW. Serotonin increases the velocity of propagation and freSerotonin increases the velocity of propagation and frequency of the migrating

14 Sagrada A, Brancaccio N, Schiavone A. 5-Hydroxytryptamine affects rat migrating myoelectric complexes through different receptor subtypes: evidence from 5-hydroxytrypophan administration. Life Sci 1990; 46: 1207-16.

15 Thomas DR, Nelson DR, Johnson AM. Biochemical effects of the antidepressant paroxetine, a specific 5-hydroxytryptamine uptake inhibitor. Psychopharmacology 1987; 93: 193-

16 Gershon MD, Jonakait GM. Uptake and release of 5-hydroxytryptamine by enteric 5-hydroxytryptaminergic eurones: effects of fluoxetine (Lilley 110140) and chlorimipramine. Br $\mathcal{F}$ Pharmacol 1979; 66: 7-9.

17 Kellow JE, Borody TJ, Phillips SF, Tucker RL, Haddad AC. Human interdigestive motility: variations in patterns from esophagus to colon. Gastroenterology 1986; 91: 386-95.

18 Kellow JE, Gill RC, Wingate DL. Prolonged ambulant recordings of small bowel motility demonstrate abnormaliies in the irritable bowel syndrome Gastroenterology 1990 98: 1208-18.

19 Kerlin P, Phillips SF. Variability of motility of the ileum and jejunum in healthy humans. Gastroenterology 1982; 82: 694 700.

20 Hopkinson 'GB, Hinsdale J, Jaffe BM. Contraction of canine stomach and small bowel by intravenous administration of stomach and small bowel by intravenous administration of serotonin. A physio

21 Pilot M-A, Thompson HH, Zara GP. Effect of 5-hydroxyryptamine on canine intestinal motility during fasting. Physiol 1983; 343: 88-9P

22 Piñeiro-Carrero VM, Clench MH, Davis RH, Andres JM, Franzini DA, Mathias JR. Intestinal motility changes in rats fter enteric serotonergic neuron destruction. Am $\mathcal{F}$ Physio 1991; 260: G232-9.

23 Di Lorenzo C, Dooley CP, Valenzuela JE. Role of fasting gastrointestinal motility in the variatility of gastrointestinal transit time assessed by hydrogen breath test. Gut 1991; 32 : transit tim

24 Akkermans LMA Vos A Hoekstra A, Roelofs JMM, Horowitz M. Effect of ICS 205-930 (a specific 5-HT eceptor antagonist) on gastric emptying of a solid meal in normal subjects. Gut 1988; 29: 1249-52.

25 Dechant KL, Clissold SP. Paroxetine. A review of its pharmacodynamic and pharmacokinetic properties, and therapeutic potential in depressive illness. Drugs 1991; 41: 225-53.

26 Sarna S, Stoddard C, Belbeck L, McWade D. Intrinsi nervous control of migrating myoelectric complexes. $A m \mathcal{F}$ Physiol 1981; 241: G16-23.

27 Lederer PC, Thiemann R, Femppel J, Domschke W, Lux G. Influence of atropine, pirenzepine and cimetidine on nocturnal gastrointestinal motility and gastric acid secretion. Scand $\mathcal{F}$ Gastroenterol 1982; 17 (suppl 72): 131-7.

28 Borody TJ, Quigley EMM, Phillips SF, Wienbeck M, Tucker RL, Haddad A, et al. Effects of morphine and atropine on motility and transit in the human ileum. Gastroenterology motility and transit

29 McIntyre AS, Thompson DG, Burnham WR, Walker E. The effect of alpha-1-adrenoreceptor agonist and antagonist administration on human upper gastrointestinal transit and motility. Aliment Pharmacol Therap 1992; 6: 415-26.

30 McIntyre AS, Thompson DG, Day S, Burnham WR, Walke ER. Modulation of human upper intestinal nutrient transit by a beta adrenoceptor mediated pathway. Gut 1992; 33: $1062-70$.

31 Sninsky CA, Davis RH, Clench MH, Thomas KD, Mathias JR. Effect of lidamidine hydrochloride and loperamide on gastric emptying and transit of the small intestine. Gastroenterology 1986; 90: 68-73.

32 Yoshida N, Mizumoto A, Iwanaga Y, Itoh Z. Effects of 5-hydroxytryptamine 3 receptor antagonists on gastrointestinal motor activity in conscious dogs. $₹$ Pharmacol Exp Ther 1991; 256: 272-8.

33 Davidson HI, Pilot M-A. Does endogenous neurona 5-hydroxytryptamine influence canine intestinal motility? 5-hydroxytryptamine in

34 Wilmer A, Coremans G, Janssens J, Vantrappen G. Effects of ondansetron, a selective $5-\mathrm{HT}_{3}$ receptor antagonist, on duodenal motility in man. Gastroenterology 1992; 102: A534.

35 Talley NJ, Phillips SF, Haddad A, Miller LJ, Twomey C, Zinsmeister AR, et al. Effect of selective $5 \mathrm{HT}_{3}$ antagonis (GR $38032 \mathrm{~F}$ ) on small intestinal transit and release of gastrointestinal peptides. Dig Dis Sci 1989; 34:1511-5.

36 Gore S, Gilmore IT, Haigh CG, Brownless SM, Stockdale H, Morris AI. Colonic transit in man is slowed by ondansetron (GR38032F), a selective 5-hydroxytryptamine receptor (type 3) antagonist. Aliment Pharmacol Therap 1990; 4: 139-

37 Costall B, Naylor RJ. 5-Hydroxytryptamine: new receptors and novel drugs for gastrointestinal motor disorders. Scand f Gastroenterol 1990; 25: 769-87. 